\title{
Dövüş Sporcularına Uygulanan Direnç, Pliometrik ve Kompleks Antrenman Yöntemlerinin Hareket Hızına Etkilerinin Karşılaştırııması ${ }^{* \dagger}$
}

\author{
Serdar BAYRAKDAROĞLU ${ }^{1}\left(\mathbb{D}\right.$, Nuri TOPSAKAL ${ }^{2}$ iD, İbrahim CAN ${ }^{3: \mathbb{D}}$ \\ ${ }^{1}$ Gümüşhane Üniversitesi, Beden Eğitimi ve Spor Yüksekokulu, Gümüşhane. \\ ${ }^{2}$ Düzce Üniversitesi, Spor Bilimleri Fakültesi, Düzce. \\ ${ }^{3}$ Iğdır Üniversitesi, Beden Eğitimi ve Spor Yüksekokulu, Iğdır.
}

Orijinal Makale

Gönderi Tarihi: 17.02.2020
Kabul Tarihi: 25.03.2020

DOI: $10.25307 /$ jssr.690103

Online Yayın Tarihi: 30.06.2020

\section{Öz}

Bu çalışmanın amacı, dövüş sporcularına uygulanan direnç, pliometrik ve kompleks antrenman yöntemlerinin hareket hızına etkilerinin karşılaştırılmasıdır. Bu amaç doğrultusunda, çalışmaya katılmak için Gümüşhane Üniversitesi Beden Eğitimi ve Spor Yüksekokulu'nda öğrenim gören ve mücadele sporlarında aktif spor yaşantısını sürdüren 30 öğrenci rastgele olarak üç farklı deney grubuna (pliometrik, direnç, kompleks antrenman grubu) ayrıldı. Araştırmanın kontrol grubu Düzce Üniversitesi Spor Bilimleri Fakültesi'nde öğrenim gören 10 öğrenciden oluşturuldu. Katılımcılara hem ön-test hem de son-test ölçümlerinde kendi kilolarının \%40 oranına karşılık olan dış yüklerde squat sıçraması egzersizi uygulandı ve ortalama hız $(\mathrm{OH})$ değeri, ortalama itme hızı $(\mathrm{OİH})$ değeri ve zirve hız $(\mathrm{ZH})$ değeri dinamik ölçüm sistemi (T-Force dinamik ölçüm sistemi) vasitasıyla elde edildi. Verilerin değerlendirilmesinde; Kolmogrov-Smirnov Normallik Testi, Kruskal Wallis ve Wilcoxon analiz yöntemleri kullanıldı. Analiz sonuçlarına göre, 8 haftalık pliometrik, direnç ve kompleks antrenmanlarından sonra gruplar arasında ağırlıklı squat sıçrama egzersizinde elde edilen $\mathrm{OH}, \mathrm{OİH}, \mathrm{ZH}$ değerleri bakımından istatistiksel yönden anlamlı bir farklılığın mevcut olduğu bulundu $(\mathrm{p}<0.05)$. Sonuç olarak, üç farklı kuvvet antrenman protokolünün de hız parametresini geliştirdiği ve gruplar arasında istatistiksel yönden anlamlı bir farklılık olduğu elde edildi. Anahtar Kelimeler: Dövüş Sporları, Antrenman, Hareket Hızı.

\section{Comparison of Effects on the Movement Velocity of Resistance, Pliometric and Complex Training Methods Applied to Martial Art Athletes}

\begin{abstract}
The aim of this study is to compare the effects of resistance, pliometric and complex training methods on the velocity of movement. For this purpose, 30 students who study at Gümüşhane University School of Physical Education and Sports and continue their active sports life in combat sports were randomly divided into three different experimental groups (plyometric, resistance, complex training group). The control group of the study consisted of 10 students studying at the Faculty of Sport Sciences of Düzce University. In both the pre-test and post-test measurements, the squat jumping exercise was performed at external loads corresponding to $40 \%$ of their own weight, and the mean velocity (MV), mean propulsive velocity (MPV), and peak velocity (PV) values were obtained by using dynamic measurement system (T-Force dynamic measurement system). In the evaluation of the data; Kolmogorov-Smirnov Normality Test, Kruskal Wallis and Wilcoxon analysis methods were used. According to the results of the analysis, it was found that there was a statistically significant difference between the groups for the 8-week pliometric, resistance and complex training applications in terms of MV, MPV and PV values obtained in the loaded-squat jump exercise $(\mathrm{p}<0.05)$. As a result, it was obtained that three different strength training protocol developed the velocity parameters and there was a statistically significant difference between the groups.
\end{abstract}

Keywords: Martial Arts, Training, Movement Velocity.

\footnotetext{
* Bu çalışma, ikinci ve üçüncü yazarın danışmanlığında yürütülen Serdar Bayrakdaroğlu'na ait doktora tezinden türetilmiștir.

† Bu çalışma, 21-24 Mart 2019 tarihleri arasında Manisa Celal Bayar Üniversitesi, Spor Bilimleri Fakültesi tarafindan düzenlenen 2. Dünya Spor Bilimleri Araştırmaları Kongre'sinde sözel sunum olarak sunulmuştur.

¥ Sorumlu Yazar: İbrahim CAN, Doç. Dr. E-posta: ibrahimcan_61_@ hotmail.com
} 


\section{GíRís}

Dövüş sanatları, genel olarak sporcunun beceri ve karakteristik özelliğini geliştirebilmek ve herhangi bir silah olmadan karşı koyabilmesini öğretebilmek gibi gelenekleri kapsayan bir spor branşıdır (Ritschel, 2008) ve bu spor branşlarında çoğunlukla başarılı bir performans için tek bir kondisyon özellik yeterli olmamaktadır. Birçok dövüş sporunda başarılı olabilmek için güç, hız, kuvvet, kondisyon, teknik gibi özelliklerin sporcularda mevcut olması gerekir (Franchini, Vecchio, Matsushigue ve Artioli, 2011). Tüm spor branşlarında olduğu gibi dövüş sporlarında da bilimsel yöntemlerden yararlanarak sporcuların performansını artırma oldukça önemli yer tutmaktadır. Sporcunun kuvvet, hız, güç, dayanıklılık, çeviklik gibi temel motorik özelliklerinin geliştirilmesi için spor branşına özgü yapılan özel çalışmalar ve antrenmanlar ile gerekmektedir (Kızılet, Atılan ve Erdemir, 2010).

Pliometrik terimi bileşik bir kelimedir ve "artma" ya da "çoğalma" anlamına gelen Yunanca "Pleythyein" kelimesinden türemiştir. Yunancada plio "daha", metric ise "ölçmek" ya da "uzunluk" anlamına gelir (Radclife ve Farentinos, 1999) ve pliometrik kelimesini daha fazla ölçmek ya da daha fazla gelişmek anlamında olduğu kabul edilir (Bompa, 2013). Chu (1998), 'bir kasın mümkün olan en kısa zamanda maksimal kuvvete ulaşmasını sağlayan egzersizler' olarak ifade etmiştir. Pliometrik antrenmanlar; gerilme - kısalma döngüsü olarak adlandırılan süreç ile oluşan yüksek şiddette bir direnç antrenman yöntemidir (Newberry ve Bishop, 2006) ve doğru uygulandığında sporcuların patlayıcı güçlerini geliştirerek sportif performanslarını artırır. Bu nedenle, kuvvet ve sürat özelliği arasında köprü oluşturan pliometrik alıştırmaların sporcuların antrenman programlarına eklenmesi sportif performansın artırılması için oldukça önemlidir (Chu, 1998; Brumitt, 2010).

Güç ya da ağırlık antrenmanları olarak da bilinen direnç antrenmanları, fiziksel kondisyonu arttırma için günümüzde kondisyonerler tarafindan uygulanan en popüler egzersiz türlerinden biri haline gelmiştir. Direnç antrenmanı, vücut kas sisteminin genellikle birtakım ekipmanlar tarafından gerçekleştirilen karşıt bir kuvvete karşı hareket etmesinin gerektiği bir egzersizi tanımlamak için kullanılır (Fleck ve Kraemer, 2014). Direnç antrenmanları; kas kuvveti, güç, hipertrofi, bölgesel kas dayanıklılı̆ı̆, hız, denge ve koordinasyon gibi özelliklerin artırılması için oynadığı rol nedeniyle genel sağlık ve fitness programlarının önemli bir unsuru haline gelmiştir (Swank ve Gagerman, 2009).

Kompleks antrenmanlar ise pliometrik ve direnç antrenmanlarının kombinasyonundan oluşan bir kuvvet antrenman yöntemidir ve kısa süreli güç verimini (daha yükseğe sıçramak ya da bir topu daha uzağa atmak gibi) geliştirmek için yararlı olduğu düşünülmektedir. Squat gibi bir kuvvet egzersiz setindeki performansın çok kısa dinlenme döneminden sonra dikey sıçrama gibi patlayıcı tipte yapılan bir egzersiz performansı ile takip edilmesi örnek olarak verilebilir (Fleck ve Kraemer, 2014). Daha spesifik olarak belirtmek gerekirse, bir kombine antrenman olan kompleks antrenman; "tek bir antrenman döneminde, setten sete değişiklik gösteren pliometrik egzersiz ile biyomekanik olarak benzer yüksek yükte uygulanan ağırlık antrenmanının değişimli olarak yapılmasıdır" (Ebber, 2002).

Vektoral bir nicelik olarak ifade edilen hareket hızı, hareketin uygulanış pozisyonları esnasında meydana gelen değişimlerin zaman ile ilgili oranı diye tanımlanır (Zatsiorsky, 
Bayrakdaroğlu, S. Topsakal, N. ve Can, İ. (2020). Dövüş sporcularına uygulanan direnç, pliometrik ve kompleks antrenman yöntemlerinin hareket hızına etkilerinin karşılaştırılması. Spor Bilimleri Araştırmaları Dergisi, 5(1), 44-54.

1998) ve direnç antrenmanlarında egzersizlerin şiddetini sayısallaştırmada kullanılan bir parametredir (Cormie vd., 2011; Gonzales-Badillo ve Sanchez-Medina, 2010; Kawamori ve Newton, 2006; Pereira ve Gomes, 2003). Aslında bir hareketin uygulanma hızı, sporcunun hareket esnasında uyguladığı aktüel bir bedensel efor için antrenörlere veya kondisyonerlere önemli bir referans olabilir. Bu olgu, daha doğru ve gerçekçi bir antrenman modeli olan ve hız-temelli direnç antrenmanları olarak isimlendirilen daha güvenilir bir efor seviyesi ortaya çıkarabilir (Gonzales -Badillo ve Sanchez-Medina, 2010).

Antrenör veya kondisyonerlerin yaptırdığı antrenmanların temel amacı; sporcuların spesifik özelliklerini geliştirip spor branşlarında daha büyük başarıların elde edilmesidir. Bu başarının elde edilmesi ve spor müsabakalarında başarılı performans için yeni yaklaşım ve antrenman programları tasarlanır. Bugüne kadar, direnç antrenmanlarında çok fazla göz ardı edilen ama oldukça önemli bir parametre olduğu kabul edilen hareket hızının gelişimi üzerine yapılan bu araştırmada elde edilecek sonuçlar, spor bilimleri literatüründeki mevcut açığı doldurmasının yanında antrenörler, kondisyonerler ve kuvvet antrenmanı yapanlara katkı sağlayacaktır. $\mathrm{Bu}$ nedenle, dövüşs sporlarında mücadele eden sporculara 8 haftalık uygulanan farklı antrenman prosedürlerinin hareket hızı üzerindeki etkilerinin karşılaştırılarak hangi yöntemin daha iyi geliştirdiğinin belirlenmesi çalışmanın amacını oluşturur.

\section{METOT}

\section{Araştırma Grubu}

Bu çalışmaya, Gümüşhane Üniversitesi Beden Eğitimi ve Spor Yüksekokulu (BESYO) ve Düzce Üniversitesi Spor Bilimleri Fakültesi'nde (SBF) eğitim gören 40 öğrenci gönüllü olarak katıldı. Gümüşhane Üniversitesi BESYO'da öğrenim gören 30 aktif mücadele sporları (kickboks, taekwondo, güreş, boks, muaythai, wushu) öğrencisi rastgele örnekleme yöntemi kullanılarak direnç antrenman grubu (DAG) pliometrik antrenman grubu (PAG) ve kompleks antrenman grubu (KAG) olmak üzere üç (3) farklı deney grubuna dağıtıldı. Araştırmanın kontrol grubunu (KG), Düzce Üniversitesi SBF'sinde öğrenim gören ve mücadele sporlarında daha önceden milli olan fakat düzenli olarak egzersiz yapmayan 10 öğrenci oluşturmaktadır. Araştırmadan önce deneklere araştırmanın amaçları ve planlamaları, uygulanacak antrenman prosedürleri, yapılacak ölçümler ile araştırmada yaşanabilecek problemler ve sorumluluklara yönelik kapsamlı açıklama yapıldı ve araştırmaya katılacak olan bireylerden Bilgilendirilmiş Onam Formu doldurmaları istendi. Araştırma, Düzce Üniversitesi Să̆llk Bilimleri Enstitüsü Girişimsel Olmayan Sağlık Araştırmaları Etik Kurulu tarafından 2016/108 karar numarası ile onaylandı. Araştırma grubunun fiziksel özelliklerine yönelik tanımlayıcı değerleri tablo 1'de verildi.

\section{Veri Toplama Araçları}

Deneklerin boy ölçümleri $0.001 \mathrm{~m}$, vücut ağırlıkları ise $0.01 \mathrm{~kg}$ doğruluk ile elektronik ölçüm aleti (Seca Corporation, Hamburg, Almanya) ile elde edildi. Tam squat hareketindeki bir tekrarlı maksimal (1TM) kuvvet testi ve 8 hafta yapılan kuvvet antrenmanları Smith makine (Esjim, IT7001, Eskişehir, Türkiye) kullanılarak yaptırıldı. Katılımcıların hız parametrelerini 
Bayrakdaroğlu, S. Topsakal, N. ve Can, İ. (2020). Dövüş sporcularına uygulanan direnç, pliometrik ve kompleks antrenman yöntemlerinin hareket hızına etkilerinin karşılaştırılması. Spor Bilimleri Araştırmaları Dergisi, 5(1), 44-54.

belirlemek için dinamik bir sistem (T-Force Dinamik Ölçüm Sistemi, Ergotech Consulting SL Murcia, İspanya) kullanıldı. Bu sistem, direnç egzersizlerinde kinetik ve kinematikleri değerlendirmek için spor bilimciler ve kondisyonerler tarafından yaygın bir şekilde kullanılır (Sanchez- Medina ve Gonzales-Badillo, 2011).Katılımcıların ağırlıklı squat sıçrama egzersizi sirasındaki hiz parametreleri ve tam squat hareketindeki 1TM değerlerini belirleyebilmek ve kuvvet antrenmanlarını uygulayabilmek için ağırlıkları 1-20 kg arasında değişen serbest ağırlıklar ve bu ağırlıkların takılabilmesi için $20 \mathrm{~kg}$ ağırlığındaki ve $220 \mathrm{~cm}$ uzunluğundaki bir olimpik bar kullanıldı (Esjim, Eskişehir, Türkiye).

Tablo 1. Katılımcıların fiziksel özellikleri

\begin{tabular}{|c|c|c|c|}
\hline Antrenman Grubu & Değişkenler & $\mathbf{n}$ & Ortalama $( \pm$ SS $)$ \\
\hline \multirow{3}{*}{ Pliometrik Antrenman Grubu } & Yaş (yıl) & 10 & $21,1( \pm 2,02)$ \\
\hline & Boy $(\mathrm{cm})$ & 10 & $175,7( \pm 4,76)$ \\
\hline & Vücut Ağırlı̆̆ $(\mathrm{kg})$ & 10 & $67,6( \pm 5,05)$ \\
\hline \multirow{3}{*}{ Direnç Antrenman Grubu } & Yaş (yıl) & 10 & $20,5( \pm 1,64)$ \\
\hline & Boy $(\mathrm{cm})$ & 10 & $178,7( \pm 4,54)$ \\
\hline & 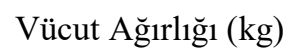 & 10 & $74,3( \pm 6,18)$ \\
\hline \multirow{3}{*}{ Kompleks Antrenman Grubu } & Yaş (yıl) & 10 & $21,3( \pm 2,35)$ \\
\hline & Boy $(\mathrm{cm})$ & 10 & $180,8( \pm 3,45)$ \\
\hline & Vücut A $\breve{g ̆}_{1 r l} \breve{g ̆ g}_{1}(\mathrm{~kg})$ & 10 & $74,7( \pm 10,5)$ \\
\hline \multirow{3}{*}{ Kontrol Grubu } & Yaş (yıl) & 10 & $20,6( \pm 2,50)$ \\
\hline & Boy $(\mathrm{cm})$ & 10 & $171( \pm 6,23)$ \\
\hline & Vücut A Ăırlığı $(\mathrm{kg})$ & 10 & $73,3( \pm 14,35)$ \\
\hline
\end{tabular}

\section{Verilerin Toplanması}

$\mathrm{Bu}$ araştırmada, ön test ve son test ölçüm yöntemi uygulandı. İki test arasında 8 haftalık bir zaman dilimi vardır. Deney gruplarının ön test ölçümleri katılımcılara yeterli dinlenme süresi verilerek ardışık olmayan iki (2) farklı günde tamamlandı. İlk gün, katılımcıların boy ve vücut ağırlığı ölçümleri alındı ve dış yük eklenerek (kendi vücut ağırlıklarının \%40’1) squat sıçraması uygulandı (Loturco, D’Angelo, Fernandes, Gil, Kobal, Cal-Abad, Kitamura, Nakamura, 2015). Katılımcılara ağırlıklı squat sıçrama egzersizi yaptırılmadan önce, alt ve üst vücut ekstremitelerini 1sındırmaları için 15 dakikalık 1sınma süresi verildi. Genel ısınma çalışmasından sonra, katılımcıların vücut ağırlığının \%40’ına karşılık gelen serbest ağırlıklar olimpik bara takıldı ve katılımcıların omuz bölgesine yerleştirilip yarım squat şeklinde üç (3) defa squat sıçrama hareketi yaptırıldı ve analiz için en iyi değer kaydedildi.

Katılımcıların squat sıçraması hareketi esnasındaki ortalama hız $(\mathrm{OH})$, ortalama itme hızı (OİH) ve zirve hız $(\mathrm{ZH})$ değerleri dinamik ölçüm sistemi ile elde edilerek otomatik olarak bilgisayara kaydedildi. İkinci gün, direnç ve kompleks antrenman gruplarında 8 haftalık antrenman programlarının uygulanmasında kullanılacak yüklenme şiddetini belirlemek için Beachle, Earle ve Wathen (2008) tarafindan tasarlanan bir tekrarlı maksimal (1TM) kuvvet test prosedürü kullanılarak katılımcıların tam squat egzersizindeki 1TM değerleri alındı. PAG antrenman programında ağırlık çalışması olmadığı için 1TM ölçümleri yapılmadı. 8 haftalık antrenmanlardan sonra yapılan son test ölçümleri bir (1) gün sürdü ve sadece ağırlıklı squat sıçrama egzersizi yaptırıldı. Ölçümlere katılan tüm katılımcılardan testlerden önceki 24 saat 
Bayrakdaroğlu, S. Topsakal, N. ve Can, İ. (2020). Dövüş sporcularına uygulanan direnç, pliometrik ve kompleks antrenman yöntemlerinin hareket hızına etkilerinin karşılaştırılması. Spor Bilimleri Araştırmaları Dergisi, 5(1), 44-54.

süresince şiddetli egzersiz yapmamaları ve testlerden 3 saat önce herhangi bir şey yememeleri istendi. Antrenman gruplarının ölçümleri, Gümüşhane Üniversitesi Beden Eğitimi ve Spor Yüksekokulu Fitness salonunda, kontrol grubunun ölçümleri ise Düzce Üniversitesi Spor Bilimleri Fakültesi fitness salonunda araştırmacılar tarafından gerçekleştirildi.

Bütün gruplara antrenmanlar haftada 3 gün uygulandı ve antrenmanlardan önce 15-20 dakika 1sınma ile stretching hareketleri yaptırıldı. Ayrıca, antrenman sonunda 10 dakikalık soğuma egzersizleri uygulandı. Gruplara 8 hafta boyunca uygulanan antrenman programları aşağıdaki tablolarda verilmiştir (Tablo 2, Tablo 3 ve Tablo 4). Tüm deney gruplarına uygulanan antrenman protokolleri, Gümüşhane Üniversitesi Beden Eğitimi ve Spor Yüksekokulu bünyesindeki fitness ve spor salonlarında gerçekleştirildi.

Tablo 2. Direnç antrenman grubunun 8 haftalık antrenman protokolü

\begin{tabular}{|c|c|c|c|c|}
\hline Egzersiz Hareketleri & Egzersiz Şiddeti & Tekrar Sayısı & Dinlenme Süresi & Set Süresi \\
\hline \multicolumn{5}{|l|}{ 1. 2. ve 3. Hafta } \\
\hline Back Squat (Yarım - 90 $)$ & $\% 70$ & 5 & 4 dakika & 3 \\
\hline Dumbbell Lunge (Ön-Arka) & Vücut ağıllığının \%40’1 & $5 \mathrm{Sağ}-5 \mathrm{sol}$ & 4 dakika & 3 \\
\hline Dead Lift & $\% 70$ & 5 & 4 dakika & 3 \\
\hline \multicolumn{5}{|l|}{ 4. 5. ve 6. Hafta } \\
\hline Front Squat (Yarım - 90) & $\% 70$ & 5 & 4 dakika & 3 \\
\hline Dumbbell Lunge (Ön-Lateral) & Vücut ağırlığının \%40’1 & $6 \mathrm{Sağ}-6 \mathrm{sol}$ & 4 dakika & 3 \\
\hline Dead Lift & $\% 70$ & 6 & 4 dakika & 3 \\
\hline \multicolumn{5}{|l|}{ 7. ve 8. Hafta } \\
\hline Back Squat (Full Squat) & $\% 70$ & 7 & 4 dakika & 3 \\
\hline Dumbbell Lunge (Ön-Arka) & Vücut ağırlığının \%40’1 & 7 Sağ - 7 Sol & 4 dakika & 3 \\
\hline Dead Lift & $\% 70$ & 7 & 4 dakika & 3 \\
\hline
\end{tabular}

Tablo 3. Kompleks antrenman grubunun 8 haftalık antrenman protokolü

\begin{tabular}{|c|c|c|c|c|}
\hline Egzersiz Hareketleri & Egzersiz Süresi & Tekrar Sayısı & Dinlenme Süresi & Set Süresi \\
\hline \multicolumn{5}{|l|}{ 1. 2. ve 3. Hafta } \\
\hline Back Squat $($ Yarım - 90 $)$ & $\% 70$ & 5 & 4 dakika & 3 \\
\hline Dumbbell Lunge (Ön-Arka) & Vücut ağırlığııın \% 40’1 & $5 \mathrm{Sağ}-5 \mathrm{Sol}$ & 4 dakika & 3 \\
\hline Rim Jumps & 20 saniye & - & 1.30 dakika & 3 \\
\hline Side to Side Single Leg Jump & 20 saniye & - & 1.30 dakika & 3 \\
\hline \multicolumn{5}{|l|}{ 4. 5. ve 6. Hafta } \\
\hline Front Squat (Yarım - 90 $)$ & $\% 70$ & 5 & 4 dakika & 3 \\
\hline Dumbbell Lunge (Ön-Lateral) & Vücut ağırlığının $\% 40$ 'ı & 6 Sağ - 6 Sol & 4 dakika & 3 \\
\hline Stadium Hops (Merdiven) & 25 saniye & - & 2 dakika & 3 \\
\hline Hexagon Drill & 25 saniye & - & 2 dakika & 3 \\
\hline \multicolumn{5}{|l|}{ 7. ve 8. Hafta } \\
\hline Back Squat (Full Squat) & $\% 70$ & 7 & 4 dakika & 3 \\
\hline Dead Lift & $\% 70$ & 5 & 4 dakika & 3 \\
\hline 5-5-5 Squat Jump (Sağlık Topu İle) & - & 2 & 4 dakika & 3 \\
\hline Barrier Cone Hops (Hurdle) & 25 saniye & - & 4 dakika & 3 \\
\hline
\end{tabular}


Bayrakdaroğlu, S. Topsakal, N. ve Can, İ. (2020). Dövüş sporcularına uygulanan direnç, pliometrik ve kompleks antrenman yöntemlerinin hareket hızına etkilerinin karşılaştırılması. Spor Bilimleri Araştırmaları Dergisi, 5(1), 44-54.

Tablo 4. Pliometrik antrenman grubunun 8 haftalık antrenman protokolü

\begin{tabular}{lcccc}
\hline Egzersiz Hareketleri & Egzersiz Süresi & Tekrar Sayısı & Dinlenme Süresi & Set Süresi \\
\hline 1. 2. ve 3. Hafta & & & & \\
Front Cone Hops & 20 saniye & - & 1.30 dakika & 3 \\
Rim Jumps & 20 saniye & - & 1.30 dakika & 3 \\
Alternating Push-Off & 20 saniye & - & 1.30 dakika & 3 \\
5-5-5 Squat jumps & - & 2 & 2 dakika & 3 \\
Side To Side Single Leg Jump & 20 saniye & - & 1.30 dakika & 3 \\
\hline 4. 5. ve 6. Hafta & & & & \\
Lateral Cone Hops & 25 saniye & - & 2 dakika & 3 \\
Stadium Hops (Merdiven) & 25 saniye & - & 2 dakika & 3 \\
Single Hurdle Leg Hops & 25 saniye & - & 2 dakika & 3 \\
Split Squat Jumps & 25 saniye & - & 2 dakika & 3 \\
Hexagon Drill & 25 saniye & - & 2 dakika & 3 \\
\hline 7. ve 8. Hafta & & & & \\
Wave Squat & 25 saniye & - & 2 dakika & 3 \\
Rim Jumps & 25 saniye & - & 2 dakika & 3 \\
Side To Side Single Leg Jump & 25 saniye & - & 2 dakika & 3 \\
Lateral Cone Hops & 25 saniye & - & 2 dakika & 3 \\
5-5-5 Squat Jumps (Sağlık Topu İle) & - & 2 & 2.5 dakika & 3 \\
\hline
\end{tabular}

\section{Verilerin Analizi}

Verilerin normal dağılıma uygunluğu Kolmogrov-Smirnov testiyle incelendi. Gruplar arası farklı1ıkların incelenmesinde, bağımsız ve ikiden fazla grupların karşılaştırılmasında normal dağılım göstermeyen ve $n<30$ olduğu değişkenler için Kruskal Wallis testi kullanıldı. Gruplar arası farklılıklar parametrik olmayan testlerde ikişerli olarak Mann Whitney U testi uygulanıp Bonferroni düzeltmesi ile değerlendirildi. Bağımlı iki grup karşılaştırmalarında normal dağglım göstermeyen ve $\mathrm{n}<30$ olduğu durumlarda Wilcoxon testi kullanıldı. Gruplar arasında farklılıklar Bonferroni testi ile incelendi. Sürekli değişkenler arasındaki korelasyonlar normal dağılım göstermeyen ve $\mathrm{n}<30$ değişkenler için Spearman korelasyon katsayısı kullanıldı.

\section{BULGULAR}

Araştırma gruplarının, gruplara göre ön ve son test hız parametrelerine yönelik sonuçlarının karşılaştırılması tablo 5'te, gruplar arası karşılaştırma tablo 6'da, gruplara göre son test - ön test farkının karşılaştırılması tablo 7'da ve grupların tamamından alınan hız parametrelerinin ön ve son test sonuçları tablo 8'de verildi. Analiz sonuçlarına göre, ön test ölçümlerinde hız parametreleri bakımından gruplar arasındaki farklılığın istatistiksel olarak anlamlı olmadığ ama 8 haftalık antrenmanlardan sonra ortalama hız, ortalama itme hızı ve zirve hız ölçümleri ortalamaları arasında istatistiksel olarak anlamlı bir farklılık olduğu elde edildi ( $\mathrm{p}<.05$; Tablo 5). Bu farklılığın, tüm hız parametreleri için pliometrik, direnç ve kompleks antrenman grubu ortalamalarının kontrol grubundan daha yüksek olduğu elde edildi (Tablo 6). 
Bayrakdaroğlu, S. Topsakal, N. ve Can, İ. (2020). Dövüş sporcularına uygulanan direnç, pliometrik ve kompleks antrenman yöntemlerinin hareket hızına etkilerinin karşılaştırılması. Spor Bilimleri Araştırmaları Dergisi, 5(1), 44-54.

Tablo 5. Katılımcıların ön test ve son test hız değerlerinin gruplara göre karşılaştırılması

\begin{tabular}{|c|c|c|c|c|c|c|c|c|c|c|}
\hline & & \multicolumn{8}{|c|}{ Gruplar } & \multirow[b]{3}{*}{$\mathbf{p}$} \\
\hline & & \multicolumn{2}{|c|}{ Pliometrik } & \multicolumn{2}{|c|}{ Direnç } & \multicolumn{2}{|c|}{ Kompleks } & \multicolumn{2}{|c|}{ Kontrol } & \\
\hline & & $\begin{array}{c}\text { Ortalam } \\
\mathbf{a}(\mathrm{ss}) \\
\end{array}$ & M (Q1-Q3) & $\begin{array}{c}\text { Ortalam } \\
\text { a (ss) }\end{array}$ & M (Q1-Q3) & $\begin{array}{c}\text { Ortalam } \\
\text { a (ss) }\end{array}$ & M (Q1-Q3) & $\begin{array}{c}\text { Ortalam } \\
\mathbf{a}(\mathrm{ss}) \\
\end{array}$ & M (Q1-Q3) & \\
\hline \multirow{3}{*}{ 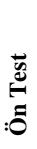 } & Ortalama $\mathrm{H} ı \mathrm{z}$ & $1.24 \pm 0.07$ & $1.21(1.2-1.26)$ & $1.27 \pm 0.11$ & $1.26(1.22-1.38)$ & $1.2 \pm 0.12$ & $1.2(1.12-1.26)$ & $1.17 \pm 0.13$ & $1.17(1.09-1.23)$ & 0.256 \\
\hline & Ortalama İtme Hızı & $1.34 \pm 0.09$ & $1.31(1.29-1.36)$ & $1.38 \pm 0.15$ & $1.35(1.31-1.5)$ & $1.28 \pm 0.14$ & $1.28(1.16-1.34)$ & $1.29 \pm 0.18$ & $1.28(1.18-1.38)$ & 0.329 \\
\hline & Zirve Hız & $2.34 \pm 0.1$ & $2.33(2.28-2.37)$ & $2.34 \pm 0.26$ & $2.3(2.25-2.58)$ & $2.34 \pm 0.2$ & $2.35(2.16-2.46)$ & $2.22 \pm 0.24$ & $2.26(2.07-2.35)$ & 0.493 \\
\hline \multirow{3}{*}{$\begin{array}{l}\vec{n} \\
\stackrel{0}{0} \\
\tilde{D}\end{array}$} & Ortalama Hız & $1.37 \pm 0.05$ & $1.4(1.35-1.4)$ & $1.4 \pm 0.09$ & $1.37(1.35-1.47)$ & $1.4 \pm 0.08$ & $1.41(1.34-1.45)$ & $1.2 \pm 0.14$ & $1.21(1.05-1.24)$ & $0.003^{*}$ \\
\hline & Ortalama İtme Hızı & $1.53 \pm 0.07$ & $1.55(1.5-1.58)$ & $1.57 \pm 0.13$ & $1.53(1.47-1.68)$ & $1.56 \pm 0.11$ & $1.59(1.5-1.65)$ & $1.32 \pm 0.2$ & $1.34(1.11-1.42)$ & $0.007^{*}$ \\
\hline & Zirve Hız & $2.58 \pm 0.08$ & $2.58(2.54-2.64)$ & $2.61 \pm 0.21$ & $2.6(2.43-2.82)$ & $2.58 \pm 0.21$ & $2.59(2.49-2.78)$ & $2.28 \pm 0.29$ & $2.25(2.03-2.54)$ & $0.026^{*}$ \\
\hline
\end{tabular}

*p<.05; M: Medyan, Q1: Birinci Persentil, Q3: Üçüncü Persentil

Tablo 6. Hız parametrelerine göre son test değerleri bakımından gruplar arası karşılaştırma

\begin{tabular}{lccc}
\hline & Ortalama Hız & Ortalama İtme Hızı & Zirve Hızı \\
\hline & \multicolumn{3}{c}{ P Değeri } \\
\hline Pliometrik - Direnç & 0,703 & 0,623 & 0,850 \\
Pliometrik - Kompleks & 0,383 & 0,307 & 0,733 \\
Pliometrik - Kontrol & $\mathbf{0 , 0 0 5}$ & $\mathbf{0 , 0 0 9}$ & $\mathbf{0 , 0 1 0}$ \\
Direnç - Kompleks & 0,880 & 0,970 & 0,762 \\
Direnç - Kontrol & $\mathbf{0 , 0 0 3}$ & $\mathbf{0 , 0 0 4}$ & $\mathbf{0 , 0 1 0}$ \\
Kompleks - Kontrol & $\mathbf{0 , 0 0 2}$ & $\mathbf{0 , 0 0 6}$ & $\mathbf{0 , 0 2 8}$ \\
\hline
\end{tabular}

Katılımcıların çalışma gruplarına göre son - ön test ölçümlerinin farkları ile ulaşılan değişken ortalamaları arası farklılıklara bakıldığında $\mathrm{OH}$, OİH ve $\mathrm{ZH}$ ölçümleri arasındaki farklılığın istatistiksel olarak anlamlı olduğu elde edildi $(\mathrm{p}<.05)$. Bu farklılık $\mathrm{OH}$ için kontrol-pliometrik ile direnç-kompleks, OİH için kontrol ile direnç ve kompleks, ZH parametresinde kontrol ve direnç ikili gruplarından kaynaklandığı sonucuna ulaşılmıştır (Tablo 7).

Tablo 7. Gruplara göre son test - ön test farkının karşılaştırılması

\begin{tabular}{|c|c|c|c|c|c|c|c|c|c|}
\hline & \multicolumn{8}{|c|}{ Grup } & \multirow[b]{3}{*}{$\mathbf{p}$} \\
\hline & \multicolumn{2}{|c|}{ Pliometrik } & \multicolumn{2}{|c|}{ Direnç } & \multicolumn{2}{|c|}{ Kompleks } & \multicolumn{2}{|c|}{ Kontrol } & \\
\hline & $\begin{array}{l}\text { Ortala } \\
\text { ma (ss) }\end{array}$ & M (Q1-Q3) & $\begin{array}{c}\text { Ortala } \\
\text { ma (ss) }\end{array}$ & M (Q1-Q3) & $\begin{array}{c}\text { Ortala } \\
\text { ma (ss) }\end{array}$ & M (Q1-Q3) & $\begin{array}{c}\text { Ortala } \\
\text { ma (ss) }\end{array}$ & M (Q1-Q3) & \\
\hline Ortalama Hız & $0.13 \pm 0.07$ & $0.12(0.07-0.2)$ & $0.13 \pm 0.05$ & $0.13(0.09-0.15)$ & $0.2 \pm 0.08$ & $0.21(0.17-0.22)$ & $0.02 \pm 0.06$ & $0.02(-0.02-0.06)$ & $0.001 *$ \\
\hline Ortalama İtme Hızı & $0.18 \pm 0.08$ & $0.18(0.13-0.26)$ & $0.19 \pm 0.07$ & $0.19(0.16-0.24)$ & $0.28 \pm 0.08$ & $0.3(0.22-0.34)$ & $0.03 \pm 0.08$ & $0.04(-0.01-0.05)$ & 0.001 \\
\hline Zirve Hiz Test & $0.23 \pm 0.13$ & $0.23(0.2-0.32)$ & $0.27 \pm 0.11$ & $0.28(0.17-0.36)$ & $0.24 \pm 0.16$ & $0.31(0.09-0.33)$ & $0.05 \pm 0.12$ & $0.06(-0.07-0.17)$ & $0.010^{*}$ \\
\hline
\end{tabular}

Çalışmaya katılan grupların tamamından alınan hız parametrelerin ön test - son test ölçümleri arasındaki farklılığa bakıldığında $\mathrm{OH}$, OİH ve $\mathrm{ZH}$ ölçümleri arasındaki farklılığın istatistiksel olarak anlamlı olduğu $(\mathrm{p}<.05)$ ve son test ölçümlerinde ulaşılan değerlerin ön test ölçümleri esnasında ulaşılan değerlerden anlamlı düzeyde daha yüksek olduğu elde edilmiştir (tablo 8). 
Bayrakdaroğlu, S. Topsakal, N. ve Can, İ. (2020). Dövüş sporcularına uygulanan direnç, pliometrik ve kompleks antrenman yöntemlerinin hareket hızına etkilerinin karşılaştırılması. Spor Bilimleri Araştırmaları Dergisi, 5(1), 44-54.

Tablo 8. Tüm katılımcıların ön test ve son test hız değerlerinin karşılaştırılması

\begin{tabular}{lccc}
\hline & Ortalama $(\mathbf{s s})$ & M (Q1-Q3) & p \\
\hline Ortalama Hız Testi Ön Test & $1.22 \pm 0.11$ & $1.22(1.16-1.27)$ & \multirow{2}{*}{$\mathbf{0 . 0 0 1}^{*}$} \\
Ortalama Hız Testi Son Test & $1.34 \pm 0.13$ & $1.35(1.29-1.43)$ & \multirow{2}{*}{$\mathbf{0 . 0 0 1}^{*}$} \\
\hline Ortalama İtme Hızı Ön Test & $1.32 \pm 0.14$ & $1.33(1.24-1.38)$ & $1.51(1.42-1.61)$ \\
Ortalama İtme Hızı Son Test & $1.49 \pm 0.17$ & $2.32(2.24-2.4)$ & $\mathbf{0 . 0 0 1}^{*}$ \\
\hline Zirve Hız Ön Test & $2.31 \pm 0.21$ & $2.56(2.41-2.67)$ & ${ }^{*}$ \\
Zirve Hız Son Test & $2.51 \pm 0.25$ & &
\end{tabular}

*p<.05; M: Medyan, Q1: Birinci Persentil, Q3: Üçüncü Persentil

\section{TARTIŞMA VE SONUÇ}

$\mathrm{Bu}$ araştırmada, dövüş sporcularına uygulanan 8 haftalık kuvvet antrenman yöntemlerinin (pliometrik, kompleks ve direnç antrenmanları) dış yük kullanılarak (vücut ağırlığının \%40’1) uygulanan squat sıçraması egzersizindeki hız parametrelerine etkileri ve hangi antrenman yönteminin hareket hızını daha iyi geliştirildiği araştırıldı. Analiz sonuçlarına göre, 8 haftalık antrenman döneminden sonra squat sıçraması egzersizindeki ortalama hız $(\mathrm{OH})$, ortalama itme hızı $(\mathrm{OIIH})$ ve zirve hız $(\mathrm{ZH})$ parametrelerinin gruplar arası anlamlı farklılık gösterdiği elde edildi $(\mathrm{p}<0.05)$. Buna göre, $\mathrm{OH}$ bakımından pliometrik, direnç ve kompleks antrenman grubu ölçümü ortalamalarının kontrol grubundan daha yüksek olduğu elde edilirken; OİH bakımından direnç ve kompleks antrenman grupları ölçüm ortalamalarının kontrol grubundan daha yüksek olduğu elde edildi. ZH değerleri bakımından ise pliometrik ve direnç antrenman grubundaki katılımcıların ölçüm ortalamalarının kontrol grubuna göre daha yüksek olduğu elde edildi. Diğer gruplar arasındaki farklılık ise istatistiksel olarak anlamlı değildir ( $>$ >.05).

Can, Özmen ve Bayrakdaroğlu (2017) tarafından farklı bireysel ve takım sporlarındaki ve en az 3 yıllık bir kuvvet antrenman geçmişine sahip olan 62 antrenmanlı sporcuda yapılan bir çalışmada, katılımcılara dış yük (vücut ağırlığının \%40’1) kullanarak uyguladıkları ağırlıklı squat sıçrama egzersizindeki $\mathrm{OH}$, OİH ve $\mathrm{ZH}$ değerleri sıraya göre $1.38( \pm, 51 \mathrm{~m} / \mathrm{sn}), 1.55$ $( \pm, 11 \mathrm{~m} / \mathrm{sn}), 2.58( \pm, 17 \mathrm{~m} / \mathrm{sn})$ olarak elde edildi. Can (2017) tarafından Avrupa ve Dünya bilek güreşi şampiyonalarına katılan ve derece yapan milli bilek güreşçiler ile hentbol 1. liginde mücadele eden hentbolculara dış yük (vücut ağırlığının \%40'1) kullanarak uyguladı̆̆ı ağırlıklı squat sıçrama egzersizi esnasındaki hız parametrelerinin karşılaştırıldığ çalışmada, milli bilek güreşçiler ve hentbolcuların $\mathrm{OH}$ değerleri sıraya göre $1.21( \pm, 09 \mathrm{~m} / \mathrm{sn}), 1.10( \pm, 07$ $\mathrm{m} / \mathrm{sn})$, OİH değerleri sıraya göre $1.29( \pm, 12 \mathrm{~m} / \mathrm{sn}), 1.17( \pm, 09 \mathrm{~m} / \mathrm{sn})$ ve $\mathrm{ZH}$ değerleri sıraya göre $2.38( \pm, 15 \mathrm{~m} / \mathrm{sn}), 2.12( \pm, 09 \mathrm{~m} / \mathrm{sn})$ olarak elde edildi. Bahsi geçen çalışmada, ağırlıklı squat egzersizi esnasındaki $\mathrm{OH}$ ve $\mathrm{ZH}$ değerleri bakımından branşlar arasındaki farklılığın istatistiksel olarak anlamlı olduğu ve milli bilek güreşi sporcularının ağırlıklı squat sıçrama egzersizinde daha iyi kaldırış hızına sahip olduğu ama OİH bakımından ise branşlar arasında anlamlı bir farklılık olmadığı elde edildi. Hentbol branşında sıçrama özelliğinin önemli bir performans kriteri olarak kabul edilmesi ve bu nedenle antrenman programlarında siçrama egzersizleri olduğu için hentbolcuların daha iyi bir sıçrama hızına sahip olması beklenirken, bilek güreşçilerin daha iyi değere sahip olmaları şaşırtıcı bir sonuç olarak ifade edilmiştir. Böyle bir sonucun ortaya çıkmasında fiziksel özellikler ve mücadele seviyesinin önemli bir faktör olduğu ileri sürüldü. Yani, bilek güreşçilerin milli sporcu olmaları ve vücut ağırlıkları daha az olduğu için daha az kilolarda kaldırış yaptıklarından daha iyi sıçrama hızına sahip oldukları ifade edildi. 
Can, Cihan, Arı ve Bayrakdaroğlu (2018) tarafından farklı branşlardaki (bilek güreşi, güreş, kickboks) milli sporculara dış bir yük (vücut ağırlığının \%40'1) kullanarak uyguladıkları squat sıçrama egzersizindeki hız değerlerini karşılaştırdıkları bir çalışmada, güreşçiler için $\mathrm{OH}$, OİH, ZH değerleri sıraya göre $1.23( \pm, 12 \mathrm{~m} / \mathrm{sn}), 1.15( \pm, 10 \mathrm{~m} / \mathrm{sn}), 1.20( \pm, 14 \mathrm{~m} / \mathrm{sn})$, bilek güreşçiler için $1.35( \pm, 14 \mathrm{~m} / \mathrm{sn}), 1.22( \pm, 12 \mathrm{~m} / \mathrm{sn}), 1.31( \pm 1.81 \mathrm{~m} / \mathrm{sn})$ ve kickbokscular için $2.31( \pm, 25 \mathrm{~m} / \mathrm{sn}), 2.12( \pm, 17 \mathrm{~m} / \mathrm{sn}), 2.25( \pm, 24 \mathrm{~m} / \mathrm{sn})$ olduğu ve diğer branşlara göre güreşçilerin daha yüksek hız değerlerine sahip olmasına rağmen, branşlar arasında farklılığın istatistiksel açıdan anlamlı olmadığı belirlendi. Farklı branşlarda mücadele eden sporcuların sıçrama egzersizlerinde elde edilen hız parametreleri farklı çalışmalarda da karşılaştırılmıştır. Dal Pupo, Detanico ve Dos-Santos (2012), sprinterlerin hem squat hem de countermovement sıçrama egzersizlerinde ZH değerlerinin voleybolculardan daha iyi olduğunu ve farklılı̆̆ın sprinterlerin antrenman protokolünden kaynaklanabileceğini ileri sürdüler. Kollias, Hatzitaki, Papaiakovou ve Giatris (2001), sprint koşucularının dikey sıçrama egzersizi hız değerlerinin voleybol, futbol ve basketbolculardan yüksek olduğunu rapor etmişlerdir. Loturco, Artioli, Kobal, Gil ve Franchini (2014) tarafından yapılan çalışmada, Brezilyalı milli karatecilere dış yük kullanılarak uyguladıkları ağırlıklı squat sıçrama egzersizindeki sıçrama hızlarını 1.23 $( \pm, 15 \mathrm{~m} / \mathrm{sn})$ olarak elde edilmiştir. Bu sonuçlara göre, sporcuların mücadele seviyeleri, vücut ağırlıkları ve spor branşına özel uygulanan antrenman protokollerinin kaldırış hızlarını etkilediği ve kaldırış hızı performansında önemli faktörler olduğu söylenebilir.

Newton, Rogers ve Volek (2006) tarafindan bayan voleybolcularda yapılan bir çalışmada, 4 haftalık ağırlıksız yapılan bir squat sıçrama hareketi antrenmanından sonra zirve hız değerinde önemli artışların (\% 8.8) meydana geldiği elde edildi. Loturco, Nakamura, Kobal, Cal-Abad, Cuniyochi ve Roschel (2015b) tarafından yapılan çalışmada, katılımcılar bar hızı artan ve azalan grup olarak 2 gruba ayrıldı ve 6 haftalık antrenman protokolünden sonra, her iki grubun da boş ve hafif ağırlıklardaki (vücut ağırlığı ve \%40'ında) ağırlıklı squat sıçrama egzersizi esnasındaki OİH değerlerini artırdıklarını elde edildi.

$\mathrm{Bu}$ çalışmada, her üç antrenman yönteminin de ağırlıklı squat sıçrama hareketi esnasındaki hız parametrelerinin gelişimine katkı sağladığı ve hız parametresinin geliştirilmesinde her üç protokolün uygulanabileceği söylenebilir. Sonuç olarak, bugüne kadar direnç antrenmanında çok fazla göz ardı edilen ama oldukça önemli bir parametre olduğu kabul edilen hareket hızı gelişimi üzerine yapılan bu çalışmadaki sonuçların, spor bilimleri literatüründe mevcut açığı doldurmanın yanında antrenörlere, kondisyonerlere ve kuvvet antrenmanları yapan bireylere katk1 sağlayacağı düşünülmektedir. 
Bayrakdaroğlu, S. Topsakal, N. ve Can, İ. (2020). Dövüş sporcularına uygulanan direnç, pliometrik ve kompleks antrenman yöntemlerinin hareket hızına etkilerinin karşılaştırılması. Spor Bilimleri Araştırmaları Dergisi, 5(1), 44-54.

\section{KAYNAKLAR}

Beachle, T.R., Earle, R.W. \& Wathen, D. (2008). Resistance training. Beachle, T.R., \& Earle, R.W. (Ed). Essentials of strength training and conditioning (381-412). United States: Human Kinetics

Brumitt, J. (2010). Core assessment and training. United States: Human Kinetics.

Bompa, T.O. (2013). Plyometrik: Sporda çabuk kuvvet antrenmanı (Çeviri: Bağırgan, T.) Ankara: Spor Yayınevi ve Kitapevi.

Can, I. (2017). Comparison of power, velocity and force parameters during loaded squat jump exercise in the handball and arm wrestling players. Journal of Education and Training Studies, 5(12), 92-98. https://doi:10.11114/jets.v5i12.2057.

Can, I., Özmen, M. \& Bayrakdaroğlu, S. (2017). Antrenmanlı sporcularda çeviklik ve ağırlıklı squat sıçrama egzersizi esnasındaki hız ve güç değerleri arasındaki ilişki. Celal Bayar Üniversitesi Beden Eğitimi ve Spor Bilimleri Dergisi, 12(2), 136-144.

Can, I., Cihan, H., Arı, E. \& Bayrakdaroğlu, S. (2018). Comparison of the velocity and power parameters during loaded squat jump exercise of national athletes in different branches. Journal of Education and Training Studies, 5(5), 16-20. https://doi.org/10.11114/jets.v6i5.3132.

Chu, D.A. (1998). Jumping into plyometrics: 100 Exercises for power \& strength. United States: Human Kinetics.

Cormie, P., McGuigan, M.R. \& Newton, R.U. (2011). Developing maximal neuromuscular power: Part 2training considerations for improving maximal power production. Sports Medicine, 41(2), 125-146. https://doi:org/10.2165/11538500-000000000-00000.

Dal-Pupo, J., Detanico, D., \& Dos-Santos, S.G. (2012). Kinetic parameters as determinants of vertical jump performance. Brazilian Journal of Kinanthropometry and Human Performance, 14(1), 41-51. https://dx.doi.org/10.5007/1980-0037.2012v14n1p41.

Ebben, W.P. (2002). Complex training: A brief review. Journal of Sports Science and Medicine, 1(2), 42-46.

Fleck, S.J. \& Kraemer, W.J. (2014). Designing resistance training programs. United States: Human Kinetics.

Franchini, E., Vecchio, F.B., Matsushigue, K.A. \& Artioli, G.G. (2011). Physiological profiles of elite judo athletes. Sport Medicine, 41(2),147-66. https://doi:org/10.2165/11538580-000000000-00000.

Gonzales-Badillo, J.J. \& Sanchez-Medina, L. (2010). Movement velocity as a measure of loading intensity in resistance training. International Journal of Sports Medicine, 31(5), 347-352.48. https://doi.org/10.1055/s-0030-1248333.

Kawamori, N. \& Newton, R.U. (2006). Velocity specificity of resistance training: Actual movement velocity versus intention to move explosively. Strength and Conditioning Journal, 28(2), 86-91.

Kızılet, A., Atılan, O. \& Erdemir, İ. (2010). 12-14 yaş grubu basketbol oyuncularının çabukluk ve sıçrama yetilerine farklı kuvvet antrenmanlarının etkisi. Atatürk Üniversitesi Beden Eğitimi ve Spor Bilimleri Dergisi; 12(2), 44-57.

Kollias, I., Hatzitaki, V., Papaiakovou, G. \& Giatsis, G. (2001). Using principal components analysis to identify individual differences in vertical jump performance. Research Quarterly for Exercise and Sports, 72(1), 63-67. https://doi.org/10.1080/02701367.2001.10608933.

Loturco, I., Artioli, G., Kobal, R., Gil, S. \& Franchini, E. (2014). Predicting punching acceleration from selected strength and power variables in elite karate athletes: A multiple regression analysis. Journal of Strength and Conditioning Research, 28(7), 1826-1832. https://doi.org/10.1519/JSC.0000000000000329.

Loturco, I., D’Angelo, R.A., Fernandes, V., Gil, S., Kobal, R., Cal-Abad, C.C., Kitamura, K. \& Nakamura, F. (2015). Relationship between sprint ability and loaded / unloaded jump tests in elite sprinters. Journal 
Bayrakdaroğlu, S. Topsakal, N. ve Can, İ. (2020). Dövüş sporcularına uygulanan direnç, pliometrik ve kompleks antrenman yöntemlerinin hareket hızına etkilerinin karşılaştırılması. Spor Bilimleri Araştırmaları Dergisi, 5(1), 44-54.

$\begin{array}{llllll}\text { of Strength } & \text { and } & \text { Conditioning } & \text { Research, } & 29(3), & 758-764 .\end{array}$
https://doi.org/10.1519/JSC.0000000000000660.

Loturco, I., Nakamura, F., Kobal, R., Gil, S., Abad, C.C., Cuniyochi, R. \& Roschel, H. (2015). Training for power and speed: Effects of increasing or decreasing jump squat velocity in elite young soccer players. Journal of Strength and Conditioning Research, 29(10), 2771-2779. https://doi.org/10.1519/JSC.0000000000000951.

Newberry, L. Bishop, M.D. (2006). Plyometric and agility training into the regimen of a patient with postsurgical anterior knee pain. Physical Therapy in Sport, 7(3), 161-167. https://doi.org/10.1016/j.ptsp.2006.05.001.

Newton, R.U., Rogers, R.A., Volek, J.S., Hakkinen, K. \& Kraemer, W.J. (2006). Four weeks of optimal load ballistic resistance training at the end of season attenuates declining jump performance of women volleyball players. Journal of Strength and Conditioning Research, 20(4), 955-961. https://doi.org/ 10.1519/R-5050502x.1

Pereira, M.I.R. \& Gomes, P.S.C. (2003). Movement velocity in resistance training. Sports Medicine, 33(6), 427438. https://doi.org/10.2165/00007256-200333060-00004.

Radcliffe, J.C. \& Farentinos, R.C. (1999). High-powered plyometrics: 77 Advanced exercises for explosive sports training. United States: Human Kinetics.

Ritschel, J. (2008). The kickboxing handball. New York: The Rosen Publication Group.

Sanchez-Medina, L. \& González-Badillo, J.J. (2011). Velocity loss as an indicator of neuromuscular fatigue during resistance training. Medicine Science in Sports and Exercise, 43(9), 1725-1734. https://doi.org/10.1249/MSS.0b013e318213f880.

Swank, A.M. \& Hagerman, P. (2009). Resistance training for special populations. USA: Delmar, Cengage Learning.

Zatsiorsky, V.M. (1998). Kinematics of human motion. United States: Human Kinetics.

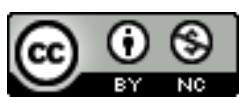

Bu eser Creative Commons Atıf-GayriTicari 4.0 Uluslararası Lisansı ile lisanslanmışır. 